\title{
MACROECONOMIC CONSEQUENCES OF DISTRIBUTIONAL CONFLICTS
}

\author{
ANDREAS SCHÄFER \\ THOMAS M. STEGER
}

\section{CESIFO WORKING PAPER NO. 2007}

CATEgOry 5: Fiscal Policy, Macroeconomics AND Growth

MAY 2007

An electronic version of the paper may be downloaded

- from the SSRN website:

www.SSRN.com

- from the RePEc website:

www.RePEc.org

- from the CESifo website:

www.CESifo-group.de 


\title{
MACROECONOMIC CONSEQUENCES OF DISTRIBUTIONAL CONFLICTS
}

\begin{abstract}
This paper aims at better understanding the inefficiency due to distributional conflicts, which are inherent in every market economy. To this end, we set up a simple general equilibrium model with the following characteristics: two groups of agents (capitalists and workers), an endogenous income tax, productive government expenditures, social transfers, and an outside option for capital. The political mechanism employed in this paper accounts for the evidence showing that the degree of organization of major interest groups has an impact on political outcomes and, in addition, allows for strategic interaction among major interest groups. We decompose the overall inefficiency into three components: (i) a fundamental time inconsistency problem; (ii) strategic interaction in the political process; (iii) heterogeneity among individuals and the resulting unavoidable conflict of interest. A numerical exercise (based on OECD data) shows that the distributional-conflict inefficiency may cause a substantial output loss of about $7 \%$.
\end{abstract}

JEL Code: E6, H2, O4.

Keywords: distributional conflict, time inconsistency, strategic interaction, heterogeneity.

Andreas Schäfer

University of Zurich

CCRS- Center for Corporate Responsibility and Sustainability

Künstlergasse 15a

8002 Zurich

Switzerland

andreas.schaefer@ccrs.unizh.ch
Thomas M. Steger

ETH Zurich

CER-Center for Economic Research

ZUE F 13

8092 Zurich

Switzerland

tsteger@ethz.ch

May 2007 


\section{Introduction}

Conflict over the distribution of resources (i.e. "distributional conflict") is an unavoidable characteristic of every market economy. We believe that the way these conflicts are carried out has first-order implications for economic efficiency and economic development. Much research has recently been devoted to less developed economies which are characterized by imperfect property rights (e.g. Benhabib and Rustichini, 1996; Strulik, 2005; Gonzalez and Neary, 2005). But even in developed economies with perfect property rights fundamental distributional conflicts prevail. These conflicts are typically carried out via the political process. The probably most important channel consists in the manipulation of the tax and expenditure system by major interest groups in their favor. ${ }^{1}$

We aim at a better understanding of the sources and consequences of distributional conflicts in developed economies. To this end, a simple general equilibrium model is set up that captures the major characteristics of modern economies, relevant for the analysis of distributional conflicts, i.e. two groups of agents (capitalists and workers), an endogenous income tax, productive government expenditures, social transfers, and an outside option for capital. We use this model to investigate the macroeconomic consequences of distributional conflicts.

The paper at hand contributes to the literature on the macroeconomic consequences of distributional conflicts along three dimensions: (i) The political mechanism, which gives rise to the equilibrium tax rates, deviates from the most commonly used political mechanism, i.e. the median voter principle. This is not to say that the median voter principle is an invalid description of political processes. However, real-world political processes are also characterized by a country's specific political institutions, its political culture, and especially by the degree of organization of major interest groups. ${ }^{2}$ For instance, empirical data show that there is a strong positive correlation between unionization rates and average tax rates across OECD economies; see Figure 1 below. This simple correlation indicates that the (relative) strength of major interest groups might affect the political outcome. The political mechanism employed in this paper, despite its simplicity, is consistent with this observation. Moreover, the model gives rise to a richer set of implications. Depending on the parameters of the model, the political equilibrium belongs to one of three regimes ("dominance of capitalists", "dominance of workers", "no group dominates"). A further advantage is that the political mechanism employed in this paper allows us to distinguish between the presence and the absence of strategic interaction in the political sphere. (ii) The analysis shows that the decentralized equilibrium is generally inefficient. An interesting result is that the decentralized tax rate can be either too high or too low. This implies that it is not in general one group which can be held responsible for an inefficient tax rate. The distributional conflict gives rise to either "weak inefficiency" (i.e. the tax rate deviates from the first-best solution but a change in the tax rate would at least hurt one group) or "strong inefficiency" (i.e. the tax rate deviates from the first-best solution and can be changed such that both groups would be better off). (iii) The main contribution of the paper lies, however, in the decomposition of the overall distributional-conflict inefficiency into

\footnotetext{
${ }^{1}$ There are, of course, other channels like the implementation of regulaltions to the advantage of specific groups. More generally, a number of real-world institutions are designed and implemented to favor specific groups in society. We focus on taxes and expenditures as an important example. However, the analysis should be considered as being more general and applicable also to other channels.

${ }^{2}$ In the median voter model all that matters is the preference of the median voter. Moreover, when it comes to the analysis of distributional conflicts among two major groups in society, the median voter principle is less instructive since it implies that it is always the larger group that can implement its preferred policy, irrespective of the political influence of the other group.
} 
three components. The first component reflects a fundamental time inconsistency problem, which is due to the fact that dominant groups are in general unable to commit to a specific policy (Acemoglu, 2003). The second component is associated with the presence of strategic interaction in the political process. The third component results from heterogeneity among individuals and the resulting unavoidable conflict of interest. Since the underlying general equilibrium model captures the major characteristics relevant for the analysis of distributional conflicts, we employ a calibrated version of the model (using OECD data) to demonstrate the numerical importance of distributional-conflict inefficiency. The model implies a proportional output loss of about $7 \%$, which indicates that the distributional-conflict inefficiency may be quite substantial. We also use the calibrated model to assess the relative importance of the three components mentioned above (time inconsistency, strategic interaction, heterogeneity).

There are, of course, a number of papers which deal with different aspects of distributional conflicts from a macroeconomic perspective. Hassler et al. (2003) employ a dynamic OLG model with endogenous redistribution, based on the median voter principle, to investigate the conditions for the "survival of the welfare state". This paper contributes substantially to our understanding on the sources of persistent and distortionary redistribution. Acemoglu (2003) argues that inefficient institutions, resulting from fundamental distributional conflicts in society, are likely to persist due to insurmountable commitment problems in the political sphere. In addition, there are three strands of well established contributions, which should be mentioned here: Romer (1975), Roberts (1977), Meltzer and Richard (1981) investigate the sources and consequences of redistribution with distortionary taxation. Kydland and Prescott (1977) and Fischer (1980) consider the time inconsistency problem in the context of capital taxation. Finally, Persson and Tabellini (1994), Alesina and Rodrick (1994), Bertola (1993) focus on the implications of distributional conflicts in a dynamic perspective. All of these papers do not, however, dig deeper into the different components of the distributional-conflict inefficiency, as they arise in every market economy, which is what we consider as our main contribution.

The paper is structured as follows: Section 2 introduces the basic model, which is employed in Section 3 to develop the decentralized equilibrium. Section 4 describes the first-best solution. The different forms of distributional-conflict inefficiencies are described in Section 5. The subsequent Section 6 decomposes the overall inefficiency into three fundamental components. The model is used in Section 7 to evaluate the quantitative importance of the inefficiency and to assess the relative importance of the different mechanisms. Finally, Section 8 provides a short summary and some conclusions.

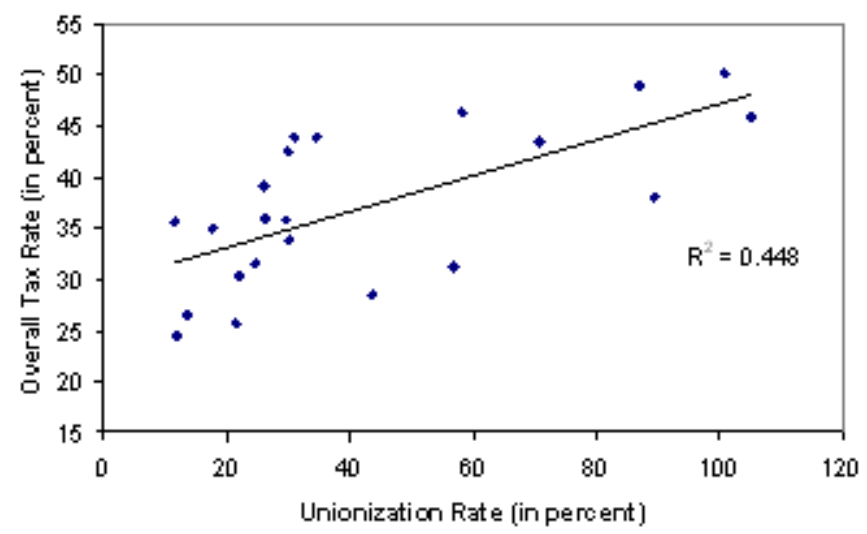

Figure 1: Tax rates and unionization rates in 2000 (OECD, 2006; ILO, 2006; Golden et al., 2006). 


\section{The structure of the model}

The model economy under study has the following characteristics: Output and factor markets are perfectly competitive. There are two types of agents, capitalists (of mass one) and workers (of mass $L$ ), which are asymmetrically affected by changes in the tax rate. Government revenues are used to finance productive government expenditures and lump-sum transfers in favor of workers. Tax revenues are collected by levying a unique income tax on capital and labor income. The model captures a fundamental distributional conflict, namely the struggle over market income net of taxes and transfers between capitalists and workers in modern societies.

\subsection{Production technology and factor prices}

The output technology for the single final output good $Y_{M}$ exhibits constant returns to scale in private inputs:

$$
Y_{M}=G^{\beta} K_{M}^{\alpha}(u L)^{1-\alpha},
$$

where $0<\alpha, \beta<1, G$ denotes productive government expenditures, $K_{M}$ is capital employed in the domestic market sector, $0 \leq u \leq 1$ is working time per worker, and $L$ is "the number" of workers. Using $G=q \tau Y_{M}$ (to be explained below) the reduced form technology reads (for details see the appendix):

$$
Y_{M}=(q \tau)^{\frac{\beta}{1-\beta}} K_{M}^{\frac{\alpha}{1-\beta}}(u L)^{\frac{1-\alpha}{1-\beta}},
$$

where $0 \leq \tau \leq 1$ is the unique tax rate levied on capital and labor income and $\alpha \leq q \leq 1$ is the share of tax revenues devoted to productive government expenditures. ${ }^{3}$ Competitive factor prices can be expressed as (for details see the appendix):

$$
\begin{gathered}
r=\alpha(q \tau)^{\frac{\beta}{1-\beta}} K_{M}^{\frac{\alpha-1+\beta}{1-\beta}}(u L)^{\frac{1-\alpha}{1-\beta}} \\
w=(1-\alpha)(q \tau)^{\frac{\beta}{1-\beta}} K_{M}^{\frac{\alpha}{1-\beta}}(u L)^{\frac{\beta-\alpha}{1-\beta}},
\end{gathered}
$$

where $r$ is the rate of return on capital and $w$ denotes the wage rate.

\subsection{Capitalists and workers}

There are two types of agents, namely capitalists and workers. Both earn a competitive market income which is subject to a unique income tax. This simplifying assumption is not at all implausible. For instance, Persson and Tabellini (2000, p. 305) notice that "in a sample of 14 OECD countries, the average effective tax rate on capital and labor were about the same (about 38\%) over the period 1991-1995."

The typical capitalist can employ his capital stock in the domestic market sector earning a rate of return $r$. The resulting market income is subject to an income tax $\tau$. Alternatively, he has the option to earn the fixed rate of return $\bar{r}>0$ by investing abroad. Following Persson and Tabellini (1991) and Lejour and Verbon (1997) we assume that investments abroad are subject to transaction costs, which accrue each period. This might be due to transaction costs associated with foreign investments resulting from, for instance, the foreign contract law, the tax system, and foreign labor market institutions. Investment

\footnotetext{
${ }^{3}$ The restriction $\alpha \leq q$ is important since the workers' preferred tax rate would otherwise turn negative. Moreover, this restriction is likely to be satisfied empirically, see Section 7.
} 
costs of investing abroad are convex in foreign investments and given by $\varepsilon \frac{K-K_{M}}{K}\left(K-K_{M}\right)$, where $K>0$ is the overall stock of capital owned by the typical domestic capitalist and $\varepsilon \geq 0$. For simplicity, we assume also that the rate of return for investments abroad is not subject to an income tax. Taken together, income of the typical capitalist is given by:

$$
y^{K}=(1-\tau) r K_{M}+\left(\bar{r}-\varepsilon \frac{K-K_{M}}{K}\right)\left(K-K_{M}\right) .
$$

The problem of the typical capitalist then reads: ${ }^{4}$

$$
\max _{K_{M}, \tau} y^{K} \quad \text { s.t. (5), (3), and } K-K_{M} \geq 0 \text {. }
$$

Notice that income is maximized by choosing $K_{M}$ and $\tau$. These decisions are made sequentially, as will be described in more detail below.

Each worker supplies $0 \leq u \leq 1$ units of labor services (measured in units of time) inelastically to the market. The wage rate per unit of labor is $w$. The resulting market income is subject to an income tax $\tau$. In addition, workers receive social transfers. The transfer per worker is the total amount of tax revenues spent on social transfers divided by the number of workers, i.e. $(1-q) \tau Y_{M} / L$. Hence, total income of the typical worker is given by:

$$
y^{L}=(1-\tau) w u+(1-q) \tau Y_{M} / L .
$$

The problem of the typical worker is as follows:

$$
\max _{\tau} y^{L} \quad \text { s.t. }(6),(4) \text {, and (2). }
$$

\subsection{The government}

The government does two things: First, it collects government revenues according the tax rate resulting from the political process. Second, it splits total tax revenues, according to the fixed share $0 \leq q \leq 1$, into productive government expenditures $G$ and lump-sum transfers in favor of workers $Q$ :

$$
\begin{gathered}
G=q \tau Y_{M} \\
Q=(1-q) \tau Y_{M} .
\end{gathered}
$$

Notice that the government is assumed to run a balanced budget, i.e. $G+Q=\tau Y_{M}$.

\subsection{The political process}

Most theoretical models on distributional conflicts rely on electoral competition and the median voter principle. ${ }^{5}$ We do not follow this route for the following reasons: First, as outlined above, the political tax rate determination process in the real world is quite complex and affected by political culture, political institutions as well as the degree of organization of major interest groups. Second, for reasons elaborated below, we think that one should not rule out the presence of strategic interaction among major interest groups a priori. ${ }^{6}$

\footnotetext{
${ }^{4}$ When maximizing with respect to $K_{M}$ capitalists take $r$ as given. This changes when deciding on the optimal tax rate, as explained below.

${ }^{5}$ According to Roemer (2001, p. 3) "probably 95\% of the formal literature in political economy since Downs has employed this particular specification."

${ }^{6}$ For a critical discussion of the Downsian model of electoral competition and the median voter principle see Roemer (2001, Chapter 1.2).
} 
We employ a shortcut formulation which allows us to take the power of major interest groups as well as the presence of strategic interaction among major interest groups into account. Specifically, it is assumed that the equilibrium tax rate can be represented as a weighted sum of the demands from the two groups:

$$
\tau=\theta \tau_{C}+(1-\theta) \tau_{L},
$$

where $0 \leq \theta \leq 1$ gives the weight of capitalists in the political process, i.e. $1-\theta$ is the weight of laborers, $0 \leq \tau_{C} \leq 1$ is the (unique) income tax rate demanded by capitalists, and $0 \leq \tau_{L} \leq 1$ is the (unique) income tax rate demanded by laborers.

It is quite plausible to argue that there is indeed some element of strategic interaction among major groups in society. This requires that both groups have, at least to some extent, resolved their internal coordination problem. Of course, an influential position is Olson (1965) who has argued that collective actions are very unlikely to occur in large groups because of inherent free rider problems. However, this theory has been questioned because it leads to a number of counterfactual implications. Medina (2006) argues that collective action problems typically exhibit multiple equilibria, including both cooperation and non-cooperation. The solution to the collective action problem, i.e. the selection of the cooperation equilibrium, then crucially depends on common beliefs individuals have about the actions of others. Moreover, Elster (1982, p. 468) stresses repeated interactions and, in the case of workers, class consciousness as mechanisms to overcome the collective action problem. ${ }^{7}$

Our modelling of the political process shares some similarities with Becker (1983), who has presented an analysis of competition among pressure groups for political influence, which in turn is instrumental to redistribution. The similarities are as follows: (i) political decisions are the result of a competition among pressure groups, voting does not play an explicit role; (ii) politicians and bureaucrats are assumed to carry out the implications of the political equilibrium; (iii) there is strategic interaction among major interest groups. Since we focus on the analysis of the resulting inefficiencies for any given political power of interest groups and not on its explanation, the key difference concerns the simplifying assumption stating that "political influence" ( $\theta$ in our notation) is exogenous and not, as in Becker (1983), endogenously determined by political pressure. ${ }^{8}$ Moreover, Becker (1983) stresses that his analysis does not necessarily contradict the importance of voting, which plays an obvious role in many political systems. Instead, he argues that interest groups may acquire enough votes by manipulating the opinions of voters because only few voters have much incentives to be well informed (Becker, 1983, p. 396).

It should also be noted that the description of the political process chosen here allows for a richer set of implications when compared to the median voter principle. In particular, since capital ownership is typically highly concentrated, the median voter principle would result in a decentralized tax rate equal to the tax rate preferred by the typical laborer. In contrast, the tax rate aggregation rule (7) gives rise to different political regimes, which crucially depend on the parameter $\theta$, as will be shown below.

\footnotetext{
${ }^{7}$ Lancaster (1973) investigates the implications of the distributional conflict in a setting of strategic interaction between capitalists and workers. Acemoglu et al. (2006) study the process of coalition formation, employing a dynamic game framework, in political environments.

${ }^{8}$ In Becker's analysis "political pressure" depends on the amount of resources allocated to produce political pressure and other characteristics, like the size of the pressure group.
} 


\section{The decentralized equilibrium}

The timing of events is as follows: (i) capitalists decide on optimal $K_{M}$; (ii) the tax rate is determined from the political process; (iii) production takes place and earnings are realized; and (iv) consumption takes place. In the case of strategic interaction among major groups, each group decides strategically, i.e. taking the aggregation rule $\tau^{*}=\theta \tau_{C}+(1-\theta) \tau_{L}$ into account. The model is solved by backward induction.

\subsection{Second stage: determination of $\tau^{*}$}

\subsubsection{Capitalists}

The problem of the agent who acts on account of the group of capitalists reads: ${ }^{9}$

$$
\max _{\tau_{C}}\left\{(1-\tau) r K_{M}\right\} \quad \text { s.t. } \quad(3) \text { and }(7),
$$

where we assume that $K_{M}>0$, which is determined at the first stage. From the first-order condition for an interior solution, one can readily derive the interior segments of capitalists' reaction function (for details see the appendix):

$$
\tau_{C}=\frac{\beta}{\theta}-\frac{1-\theta}{\theta} \tau_{L}
$$

Several aspects should be observed: (i) The slope of this reaction curve, which is exclusively determined by the parameter reflecting the relative importance of the two groups $\theta$, is $\frac{\partial \tau_{C}}{\partial \tau_{L}}=-\frac{1-\theta}{\theta}<0$; (ii) If capitalists alone could determine the tax rate, i.e. $\theta=1$, one gets $\tau=\tau_{C}=\beta$, which is the Barrovian result (Barro, 1990). (iii) If the capitalist's political influence becomes negligible, i.e. $\theta \rightarrow 0$, they would like to opt for lowest feasible tax rate such that the resulting $\tau$ still is $\beta$. Since we have imposed $\tau_{C} \in[0,1]$ the complete reaction function is given by (for details see the appendix):

$$
\tau_{C}=\left\{\begin{array}{cccc}
1 & \text { for } & \frac{\beta}{\theta}-\frac{1-\theta}{\theta} \tau_{L} & >1 \\
\frac{\beta}{\theta}-\frac{1-\theta}{\theta} \tau_{L} & \text { for } & 0 \leq \frac{\beta}{\theta}-\frac{1-\theta}{\theta} \tau_{L} & \leq 1 \\
0 & \text { for } & \frac{\beta}{\theta}-\frac{1-\theta}{\theta} \tau_{L} & <0
\end{array} .\right.
$$

\subsubsection{Workers}

The problem of the agent acting on account of workers is as follows (for details see the appendix):

$$
\max _{\tau_{L}}\left\{(1-\tau) w u+(1-q) \tau Y_{M} / L\right\} \quad \text { s.t. } \quad(2),(4), \text { and }(7) .
$$

From the first-order condition for an interior solution, one can readily derive the interior segments of the workers' reaction function to read (see the appendix):

$$
\tau_{L}=\frac{(\alpha-1) \beta}{(1-\theta)(\alpha-q)}-\frac{\theta}{1-\theta} \tau_{C}
$$

To enable a direct comparison with (9), we solve the preceding equation for $\tau_{C}$ :

$$
\tau_{C}=\frac{(\alpha-1) \beta}{\theta(\alpha-q)}-\frac{1-\theta}{\theta} \tau_{L}
$$

\footnotetext{
${ }^{9}$ Notice that we can ignore capital income earned in the outside option since this component is independent of $\tau$.
} 
Several points are worth being noticed: (i) Remember that we have imposed the restriction $\alpha<q \leq 1$, which guarantees that the first term on the RHS is indeed positive. If $\alpha>q$ the reaction function of workers would be located in the negative quadrant, which is not compatible with $0 \leq \tau_{C} \leq 1$. Moreover, for $q<1$ the worker's reaction function always lies above the capitalist's reaction function since $\frac{(\alpha-1) \beta}{\theta(\alpha-q)}>\frac{\beta}{\theta}$. (ii) The reaction curve of the two groups run parallel to each other. This can be seen by inspecting (12), which implies $\frac{\partial \tau_{C}}{\partial \tau_{L}}=-\frac{1-\theta}{\theta}$. As a consequence, the political equilibrium $\left(\tau_{C}^{*}, \tau_{L}^{*}\right)$ will be a corner solution for at least one group provided that $q<1$. (iii) Assuming that there are no transfers to workers $(q=1)$ both groups prefer the same tax rate, i.e. $\tau^{*}=\tau_{L}^{*}=\tau_{C}^{*}=\beta$. In this case the two reaction curves are identical and given by $\tau_{C}=\frac{\beta}{\theta}-\frac{1-\theta}{\theta} \tau_{L}$; see equ. (9) and (12).

If the worker's political impact becomes small, i.e. $\theta \rightarrow 1$, they would like to opt for the highest feasible tax rate (see (11)) to prevent a solution $\tau^{*}=\beta$. Since $\tau_{L} \in[0,1]$ the complete reaction function is given by (for details see the appendix):

$$
\tau_{L}=\left\{\begin{array}{cccc}
1 & \text { for } & \frac{(\alpha-1) \beta}{(1-\theta)(\alpha-q)}-\frac{\theta}{1-\theta} \tau_{C} & >1 \\
\frac{(\alpha-1) \beta}{(1-\theta)(\alpha-q)}-\frac{\theta}{1-\theta} \tau_{C} & \text { for } & 0 \leq \frac{(\alpha-1) \beta}{(1-\theta)(\alpha-q)}-\frac{\theta}{1-\theta} \tau_{C} \leq 1 \\
0 & \text { for } & \frac{(\alpha-1) \beta}{(1-\theta)(\alpha-q)}-\frac{\theta}{1-\theta} \tau_{C} & <0
\end{array} .\right.
$$

Finally, it should be noted that income is constant along the interior branch of the reaction curves.

\subsubsection{Political equilibria}

We are now in the position to determine the aggregate tax rate, which is supported by a political equilibrium. Depending on the underlying parameter constellation, there are three possible solutions for the aggregate tax rate $\tau^{*}=\theta \tau_{C}^{*}+(1-\theta) \tau_{L}^{*}$. These cases are illustrated by Figure 1 and summarized in Table 1 . Notice that the reaction curve of capitalists (dashed line) hits the $\tau_{L}$-axis at $\frac{\beta}{1-\theta}$ and the reaction curve of workers (solid line) hits the $\tau_{L}$-axis at $\frac{(\alpha-1) \beta}{(1-\theta)(\alpha-q)}$.

Case (1) is labelled dominance-of-workers regime $(D L)$ : Provided that $\frac{(\alpha-1) \beta}{(1-\theta)(\alpha-q)}<1$ (implying $\frac{\beta}{1-\theta}<1$ ), one gets $\tau_{C}^{*}=0$ and $\tau_{L}^{*}=\frac{(\alpha-1) \beta}{(1-\theta)(\alpha-q)}<1$. The aggregate tax rate is then given by $\tau_{D L}^{*}=\frac{(\alpha-1) \beta}{\alpha-q}<1 .{ }^{10}$ Case $(2)$ is dubed no-group-dominates regime $(N D)$ : For $\frac{\beta}{1-\theta}<1 \wedge \frac{(\alpha-1) \beta}{(1-\theta)(\alpha-q)}>1$ we have $\tau_{C}^{*}=0$ and $\tau_{L}^{*}=1$. The aggregate tax rate therefore is $\tau_{N D}^{*}=1-\theta$. Case (3) is denoted as dominance-of-capitalists regime $(D C)$ : If $\frac{\beta}{1-\theta}>1$ (implying that $\frac{(\alpha-1) \beta}{(1-\theta)(\alpha-q)}>1$ ), then $\tau_{C}^{*}=\frac{\beta-(1-\theta)}{\theta}$ and $\tau_{L}^{*}=1$. The aggregate tax rate in this case reads $\tau_{D C}^{*}=\theta \frac{\beta-(1-\theta)}{\theta}+(1-\theta)=\beta$.

\footnotetext{
${ }^{10}$ Notice that $\tau_{D L}^{*}<1$ since we have assumed here that $\frac{(\alpha-1) \beta}{(1-\theta)(\alpha-q)}<1$ and $\theta \in[0,1]$.
} 


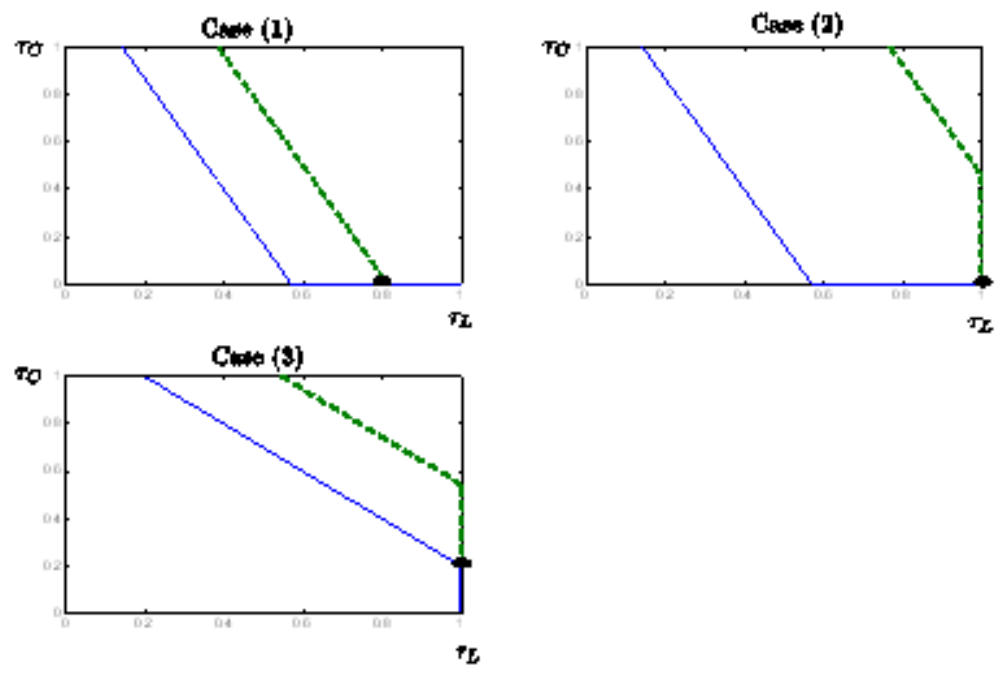

Figure 2: Reaction functions.

Table 1 provides a summary of the results described above to ease the development of an economic intuition. Consider the regime "dominance of workers". If the political impact of workers is sufficiently high in the specific sense that the measure of their importance exceeds their desired tax rate, i.e. $1-\theta>\frac{(\alpha-1) \beta}{\alpha-q}$, then workers are able to implement their preferred tax rate $\frac{(\alpha-1) \beta}{\alpha-q}$ by strategically demanding a tax rate of unity (Case (1)). ${ }^{11}$ On the other hand, if capitalists are sufficiently powerful in the specific sense that $\theta>1-\beta$, then capitalists manage to implement their desired tax rate $\beta$ by strategically demanding a tax rate of zero (Case (3)). ${ }^{12}$ Finally, if both conditions for political dominance are violated the equilibrium tax rate is $1-\theta$ (Case $(2))$.

Table 1: Different political regimes and the equilibrium tax rate.

\begin{tabular}{|l|c|c|}
\hline \multicolumn{1}{|c|}{ Regime } & Condition & Equilibrium tax rate \\
\hline \hline Case (1): Dominance of workers & $1-\theta \geq \frac{(\alpha-1) \beta}{\alpha-q}$ & $\tau_{D L}^{*}=\frac{(\alpha-1) \beta}{\alpha-q}$ \\
\hline Case (2): No group dominates & $1-\theta<\frac{(\alpha-1) \beta}{\alpha-q} \wedge 1-\theta>\beta$ & $\tau_{N D}^{*}=1-\theta$ \\
\hline Case (3): Dominance of capitalists & $1-\theta \leq \beta$ & $\tau_{D C}^{*}=\beta$ \\
\hline
\end{tabular}

Next we turn to the equilibrium tax rate assuming that the two groups cannot solve their internal coordination problem such that there is no strategic interaction in the political process. In this case, the aggregate tax rate, denoted as $\tilde{\tau}^{*}$, is given by:

$$
\tilde{\tau}^{*}=\theta \beta+(1-\theta) \frac{(\alpha-1) \beta}{\alpha-q} .
$$

Without strategic interaction in the political sphere, the equilibrium tax rate is simply a linear combination of the tax rates which maximizes income of the respective groups.

\footnotetext{
${ }^{11}$ This should be interpreted in a metaphorical sense: Under strategic interaction workers demand the "highest admissible tax rate". In the real world there might be bounds on the "highest admissible tax rate". For instance, it is quite plausible to argue that a tax rate demand which is "too high" reduces the public support in the political process.

${ }^{12}$ The fact that capitalists are more likely to implement their desired tax rate as $\beta$ increases is due to the fact that workers always desire a higher tax rate than $\beta$ and hence it becomes in fact easier for capitalists to implement their preferred tax rate as $\beta$ increases.
} 
We now have four different solutions for the equilibrium tax rate, i.e. $\tau_{D L}^{*}, \tau_{N D}^{*}, \tau_{D C}^{*}$, and $\tilde{\tau}^{*}$. How do these compare to each other? To illustrate this point, assume that the underlying set of parameters satisfies the restriction $\alpha<q<1$, such that $\frac{(\alpha-1) \beta}{\alpha-q}>\beta$ holds. Figure 2 shows the resulting tax rates as a function of $\theta$. The equilibrium tax rate, assuming strategic interaction among major interest groups, is represented by the bold solid line, which comprises three segments: (i) $\frac{(\alpha-1) \beta}{\alpha-q}$ for $1-\theta \geq \frac{(\alpha-1) \beta}{\alpha-q}$; (ii) $1-\theta$ for $\beta<1-\theta<\frac{(\alpha-1) \beta}{\alpha-q}$; and (iii) $\beta$ for $1-\theta \leq \beta$. In addition, the equilibrium tax rate in the absence of strategic interaction as a function of $\theta$ is shown by the dashed curve.

Figure 2 suggests that strategic interaction among major interest groups induces a higher tax rate compared to the case of no strategic interaction provided that laborers are strong in the specific sense $\theta<\theta^{*}=\frac{\alpha-q+\beta(1-\alpha)}{\alpha+\beta-q(1+\beta)} \cdot{ }^{13}$ Conversely, strategic interaction induces a lower tax rate provided that capitalists are strong in the sense $\theta>\theta^{*}$. Moreover, it is interesting to see that a tax rate determination according to the median voter principle would yield the other extreme, i.e. $\tau^{*}=\frac{(\alpha-1) \beta}{\alpha-q}$ for $\theta<0.5$ and $\tau^{*}=\beta$ for $\theta \geq 0.5$, provided that one interprets $\theta$ as population share.

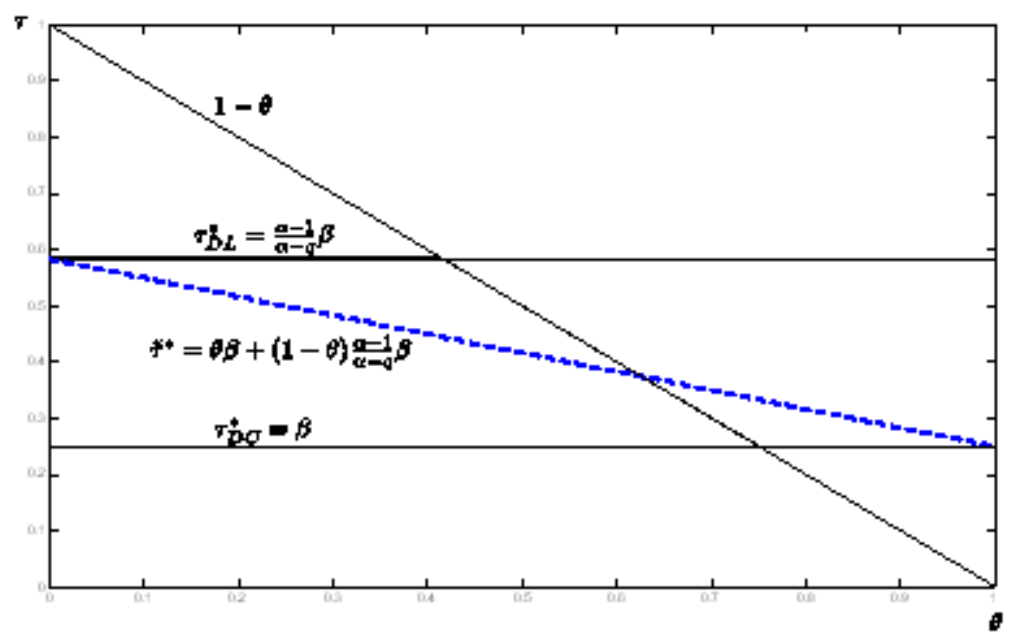

Figure 3: Equilibrium taxes.

The ranking of the four solutions can be summarized as follows:

$$
0<\tau_{D C}^{*}<\tau_{N D}^{*}, \tilde{\tau}^{*}<\tau_{D L}^{*}<1 .
$$

\subsection{First stage: determination of $K_{M}$}

At the first stage, capitalists decide on optimal $K_{M}$. By doing so, they take the equilibrium tax rate $\tau^{*}$ as given. Optimal $K_{M}$ is determined by the first-order condition $\left(1-\tau^{*}\right) r=$ $\bar{r}-\varepsilon \frac{K-K_{M}}{K}$, which can be stated more explicitly as follows:

$$
(1-\tau) \alpha(q \tau)^{\frac{\beta}{1-\beta}} K_{M}^{\frac{\alpha-1+\beta}{1-\beta}}(u L)^{\frac{1-\alpha}{1-\beta}}=\bar{r}-\varepsilon \frac{K-K_{M}}{K} .
$$

This equation implicitly determines the equilibrium allocation $K_{M}^{*}$ as a function of model parameters and $\tau$, i.e. $K_{M}^{*}=K_{M}(\bar{r}, q, \alpha, \beta, u, L, \varepsilon ; \tau)$. Unfortunately, this equation cannot

\footnotetext{
${ }^{13}$ The critical value $\theta^{*}$ results from $1-\theta=\theta \beta+(1-\theta) \frac{(\alpha-1) \beta}{\alpha-q}$.
} 
be solved analytically for $K_{M}$. However, for the special case $\varepsilon=0$ (i.e. no investment costs) an explicit solution is readily found:

$$
K_{M}^{*}=\left(\frac{\bar{r}}{(1-\tau) \alpha}\right)^{\frac{1-\beta}{\alpha-1+\beta}}(q \tau)^{\frac{\beta}{1-\alpha-\beta}}(u L)^{\frac{1-\alpha}{1-\alpha-\beta}} .
$$

This solution shows that the domestic capital supply is determined by the profitability of the outside option $\bar{r}$, the tax rate $\tau$ (which unfolds two opposing effects), and the amount of labor supplied to the domestic market sector.

\subsection{The decentralized equilibrium}

At this stage we have determined the equilibrium tax rate $\tau^{*}$ as well as the equilibrium capital allocation $K_{M}^{*}$. Moreover, since the equilibrium amount of capital in the domestic market sector, $K_{M}^{*}$, can be written as a function of the tax rate $\tau$, we can express income of capitalists and workers (equ. (5) and (6)) as a function of the tax rate only. Hence, $K_{M}=K_{M}(\tau)$ together with (5) and (6) gives:

$$
\begin{gathered}
y^{K}(\tau)=(1-\tau) r(\tau) K_{M}(\tau)+\left(\bar{r}-\varepsilon \frac{K-K_{M}(\tau)}{K}\right)\left(K-K_{M}(\tau)\right) \\
y^{L}(\tau)=(1-\tau) w(\tau) u+(1-q) \tau Y_{M}(\tau) / L .
\end{gathered}
$$

Figure 4 illustrates income of capitalists $y^{K}(\tau)$, income of workers $y^{L}(\tau)$, and aggregate income $y^{K}(\tau)+L y^{L}(\tau)$ as a function of the tax rate. ${ }^{14}$ It can be recognized that $y^{K}(\tau)$ and $y^{L}(\tau)$ follow an inverted U-shape pattern. Both $y^{K}(\tau)$ and $y^{L}(\tau)$ increase initially with the tax rate because an increase in $\tau$ leads to larger tax revenues, more productive government spending, a rise in the marginal product of capital and labor, and hence an increase in competitive factor prices. On the other hand, income net of taxes decreases with the tax rate simply because the tax burden rises. Furthermore, in the case of workers, there is an additional effect since social transfers increase, given $q$, with tax revenues. This describes the mechanics of the base model with $\bar{r}=0 .{ }^{15}$

The existence of a capital outside option, i.e. $\bar{r}>0$, together with foreign investment costs, i.e. $\varepsilon>0$, adds the following mechanisms of tax rate changes. In this case, domestic capital supply becomes endogenous and hence the income tax becomes distortionary. As $\tau$ increases, capitalists tend to shift capital abroad. This reallocation causes the marginal (and average) foreign investment costs to increase. Hence, $y^{K}(\tau)$ decreases strongly as $\tau$ rises above a certain threshold.

\footnotetext{
${ }^{14}$ The underlying set of parameters is described in Table 2 below.

${ }^{15}$ It should be noticed that the income tax does not, in this case, bias any private allocation decisions. Nonetheless, there is a unique first-best tax rate, i.e. a unique tax rate which balances marginal benefits and costs of a change in the tax rate from the social perspective.
} 


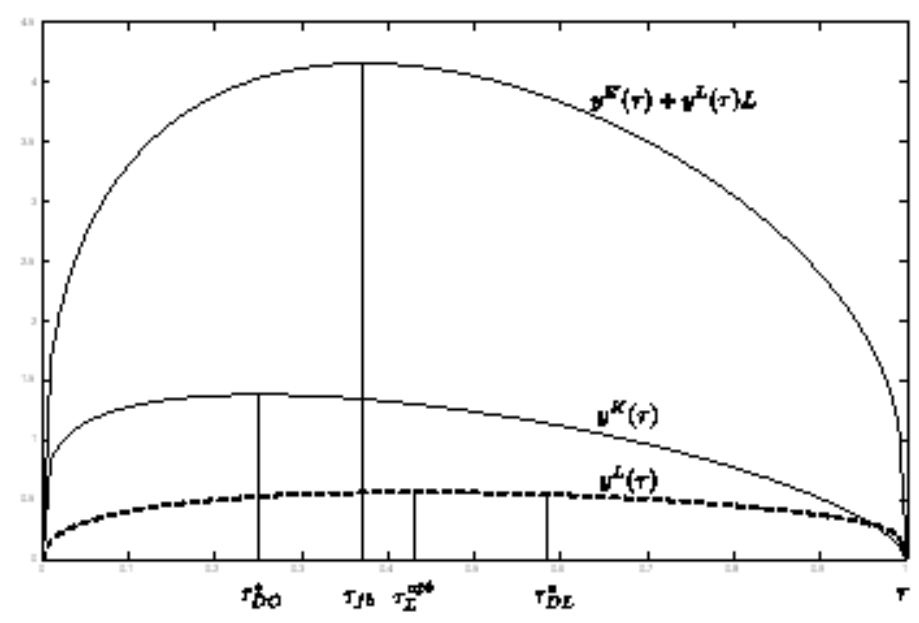

Figure 4: Income as a function of the tax rate.

\section{The first-best solution}

The first-best tax rate is the solution to the following social planner's problem: ${ }^{16}$

$$
\max _{\tau}\left\{y^{K}(\tau)+L y^{L}(\tau)\right\} \quad \text { s.t. } \quad(2),(4),(7), \quad(17) \text {, and (18). }
$$

where the equilibrium amount of capital $K_{M}$ is determined by (15). Once more, an analytical solution is not available for the general case. Therefore, we will revert to numerical procedures in the subsequent analysis.

There is, however, an interesting benchmark case, which enables an explicit solution. For the special case $\bar{r}=0$ the unique first-best tax rate is given by (for details see the appendix):

$$
\tau_{f b}=\frac{\beta}{q}
$$

which is increasing in the productivity of governmental expenditures $\beta$ and declining in the share of the budget allocated to productive government expenditures $q$.

\section{Distributional-conflict inefficiencies}

After having characterized the decentralized equilibrium and the first-best solution, we are ready to investigate the inefficiency due to the distributional conflict inherent in every market economy. Consider the situation displayed in Figure 4. The decentralized tax rate lies somewhere between $\tau_{D C}^{*}$ and $\tau_{D L}^{*}$ (both are indicated by vertical lines). Given the parameters of the model, the decentralized tax rate is crucially determined by the relative political power of capitalists and workers, as captured by $\theta$. The unique first-best tax rate, on the other hand, is indicated by the vertical line at $\tau_{f b}$. There are at least two important observations which are worth being discussed.

First, the decentralized tax rate can be either too high or too low. In a dominance of capitalist regime, the decentralized tax rate is too low. In contrast, in a dominance

\footnotetext{
${ }^{16}$ Here the first-best tax rate is determined by income maximization. Alternatively, the first-best tax rate could be determined by maximizing a utilitarian welfare function. Both procedures yield the same solution provided that a lump-sum transfer scheme is available.
} 
of workers regime, the decentralized tax rate is too high. The fact that the decentralized tax rate may deviate from the first-best tax rate indicates that there is at least weak inefficiency. ${ }^{17}$ This implies that, at a theoretical level, the social planner could implement the first-best tax rate, thereby increasing aggregate income, and subsequently use a lumpsum transfer scheme to realize any desired income distribution.

Second, provided that the tax rate is to the right of $\tau_{L}^{o p t}$ (the tax rate which maximizes the workers' income), the decentralized equilibrium exhibits strong inefficiency. ${ }^{18}$ This means that a reduction in the tax rate would not only increase aggregate income but would clearly make both groups better off. The finding of strong inefficiency points to substantial imperfections in the politico-economic equilibrium. The reasons behind this failure will be discussed in the next section.

\section{A decomposition of the overall inefficiency}

The extent of the distributional-conflict inefficiency can be measured either by the gap between the first-best tax rate and the decentralized tax rate, i.e. $\Delta \tau=\tau_{f b}-\tau^{*} \gtreqless 0$, or by the gap between aggregate income evaluated at the first-best tax rate and aggregate income evaluated at the decentralized tax rate, i.e. $\Delta y=y\left(\tau_{f b}\right)-y\left(\tau^{*}\right) \geq 0$.

\subsection{Time inconsistency due to lack of commitment}

The finding of strong inefficiency is due to a time inconsistency problem inherent in the market economy. There are two critical assumptions which give rise to this time inconsistency problem: First, the existence of a sufficiently profitable outside option for capitalists. Second, the underlying timing of events. More specifically, the assumption that capitalists first decide on their investments and then the political process determines the equilibrium tax rate is crucial. The assumption on the underlying timing of events is motivated by the observation that the relevant time horizon for foreign (direct) investments typically exceeds the time horizon underlying political tax change decisions.

The basic logic behind the time inconsistency result runs as follows: When workers decide on their preferred tax rate, they take the amount of capital invested in the domestic market sector as given. Capitalists, on the other hand, anticipate the equilibrium tax rate resulting from the political process at the second stage. Provided that workers are sufficiently powerful, i.e. $\theta$ is sufficiently low, the anticipated tax rate can be so high that capitalists invest a significant amount of capital abroad. As a result, the workers' income is depressed through two channels: First, a lower amount of capital invested in the domestic market sector reduces the wage rate because capital is complementary to labor. Second, a higher tax rate implies a lower amount of capital invested in the domestic market sector, which leads to a lower domestic capital income; notice that, in the relevant range, capital income in fact decreases with the tax rate. Hence, tax revenues from capital income, total tax revenues and, given $q$, the amount of social transfers in favor of workers fall.

We can use Figure 4 to illustrate the inefficiency as measured by $\Delta \tau=\tau^{*}-\tau_{f b}$. The time inconsistency problem can be easily eliminated from the model by reversing the timing of events. If workers decide on their preferred tax rate before capitalists invest, the time inconsistency problem vanishes. The reason is that, by construction, workers now take the negative consequences of a higher tax rate due to the two channels described above into

\footnotetext{
${ }^{17}$ To be precise, weak inefficiency labels a situation where $y^{K}\left(\tau^{*}\right)+y^{L}\left(\tau^{*}\right)<y^{K}\left(\tau_{f b}\right)+y^{L}\left(\tau_{f b}\right)$ holds.

${ }^{18}$ Strong inefficiency is characterized by $y^{K}\left(\tau^{*}\right)<y^{K}\left(\tau_{f b}\right)$ and $y^{L}\left(\tau^{*}\right)<y^{L}\left(\tau_{f b}\right)$.
} 
account. The preferred tax rate in this case is $\tau_{L}^{\text {opt }}$, i.e. the tax rate which maximizes the income of workers. Hence, the inefficiency due to the time inconsistency problem is given by $\Delta \tau=\tau_{D L}^{*}-\tau_{L}^{o p t}$.

The time inconsistency problem is basically due to the lack of a commitment technology. One could argue that workers are in fact better off if they could commit to demand a tax rate according to $\tau_{L}^{o p t}=\theta \tau_{C}+(1-\theta) \tau_{L}$ instead of $\tau_{D L}^{*}=\theta \tau_{C}+(1-\theta) \tau_{L}$. This would indeed be optimal in the pre-investment situation. In the post-investment situation, however, this solution is not incentive compatible anymore. Therefore, any attempt to commit to a strategy according to $\tau_{L}^{o p t}=\theta \tau_{C}+(1-\theta) \tau_{L}$ is not credible. Capitalists understand this commitment problem and hence correctly anticipate the strategy $\tau_{D L}^{*}=\theta \tau_{C}+(1-\theta) \tau_{L}$.

It is instructive to view this problem from a slightly different perspective. Acemoglu (2003) has recently argued that a Political Coase Theorem is generally impossible. His main argument stresses the fact that every contract needs a third party which enforces the contract. Once dominant groups are involved, this enforcement is not guaranteed anymore. This is due to the fact that dominant groups can, by definition, control the government and hence there is in fact no independent superordinate third party.

\subsection{Strategic interaction in the political process}

Does the existence of strategic interaction among major interest groups intensify or moderate the distributional-conflict inefficiency? At a general level, the answer to this question is ambiguous. Three points are, nonetheless, worth being emphasized in this context.

First, strategic interaction gives rise to the same tax rate, compared to the case of no strategic interaction, provided that $\theta=\theta^{*}=\frac{\alpha-q+\beta(1-\alpha)}{\alpha+\beta-q(1+\beta)}$ (see footnote 12). In this case, strategic interaction cannot exert an impact on $\Delta \tau$. Moreover, notice that strategic interaction leads to a higher (lower) decentralized tax rate whenever $\theta<\theta^{*}\left(\theta>\theta^{*}\right)$.

Second, consider the case $\bar{r}=0$ such that $\tau_{f b}=\beta / q .{ }^{19}$ Assuming that $\theta \neq \theta^{*}$, strategic interaction always magnifies the inefficiency provided that $q=\alpha+\beta$. This condition implies that the first-best tax rate $\tau_{f b}=\beta / q$ equals the decentralized tax rate for $\theta=\theta^{*}$; remember that for $\theta=\theta^{*}$ the decentralized tax rate with and without strategic interaction coincide. This constellation represents an important benchmark case. Since strategic interaction always leads to a higher (lower) decentralized tax rate whenever $\theta<\theta^{*}\left(\theta>\theta^{*}\right)$, it follows that the gap $\Delta \tau$ is always larger, in absolute terms, under strategic interaction.

Third, the reverse result, strategic interaction moderates the inefficiency, is more likely to occur when either (i) the first-best tax rate is close to the tax rate preferred by laborers and when laborers are strong in the sense $\theta<\theta^{*}$ or (ii) the first-best tax rate is close to the tax rate preferred by capitalists and when capitalists are strong in the sense $\theta>\theta^{*}$. In this respect, it is interesting to notice that the first-best tax rate, assuming that $\bar{r}=0$, can be represented as an average of the tax rates preferred by the two groups according to:

$$
\tau_{f b}=a \tau_{D L}^{*}+(1-a) \tau_{D C}^{*},
$$

where $a=\frac{q-\alpha}{q}>0$. Hence, if (i) $\alpha$ is either close to $q$ and $\theta>\theta^{*}$ or (ii) $\alpha$ is close to zero and $\theta<\theta^{*}$, then strategic interaction is more likely to moderate the inefficiency. The fact that strategic interaction can indeed moderate the inefficiency is, of course, a second best implication. Given an inefficiency $\tau_{f b} \neq \tau^{*}$, the presence of an additional imperfection in the political sphere can moderate the inefficiency provided that $\tau_{f b}$ is "close" to either $\tau_{D L}^{*}$ or $\tau_{D C}^{*}$ simply because strategic interaction pushes the decentralized tax rate more towards $\tau_{D L}^{*}$ or $\tau_{D C}^{*}$ if one group is strong or even dominates the tax rate determination process.

\footnotetext{
${ }^{19}$ The basic argument also holds true in the more general case $\bar{r}>0$.
} 
Taken together, strategic interaction is likely to magnify the inefficiency provided that the parameter restriction $q=\alpha+\beta$ approximately holds true. Considering empirically plausible values of the relevant parameters, $q \approx 0.6, \alpha \in[0.3,0,4]$ and $\beta \in[0.2,0.3]$, this restriction is not unlikely to be roughly satisfied in reality. Moreover, the extent to which strategic interaction magnifies the inefficiency depends on the fact whether one group is strong in the sense $\theta \neq \theta^{*}$.

Figure 5 illustrates the issues discussed above. It shows the proportional welfare loss $\frac{y\left(\tau_{f b}\right)-y\left(\tau^{*}\right)}{y\left(\tau_{f b}\right)}$ with strategic interaction (solid curve) and without strategic interaction (dashed curve) as a function of $\theta \cdot{ }^{20}$ The three plots differ with respect to the underlying value of $\beta$. Consider at first plot (b), which assumes $\beta \cong 0.243$. In this case, strategic interaction always magnifies the output loss due to distributional conflict (i.e. the solid curve lies always above the dashed curve). ${ }^{21}$ However, plot (a), based on $\beta=0.15$, and plot (c), assuming $\beta=0.3$, show that this need not be the case. For either low or high values of $\beta$, strategic interaction can in fact moderate the distributional-conflict inefficiency (i.e. there is a range of $\theta$ such that the solid curve lies below the dashed curve). This phenomenon occurs, however, only within small ranges of $\theta$. In summary, this little numerical exercise suggests once more that strategic interaction is likely to magnify the welfare loss resulting from distributional conflict.

(a) Prop. welfare loss $(\beta=0.15)$

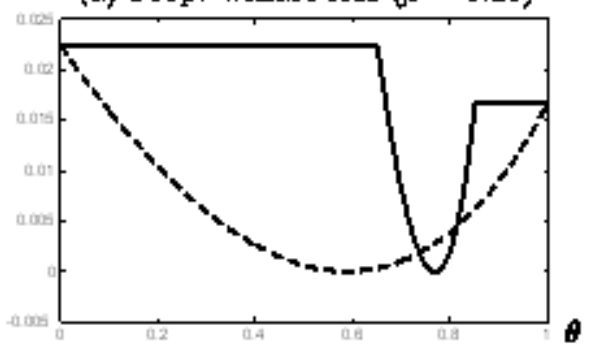

(c) Prop, welfare loss $(\beta=0.8)$

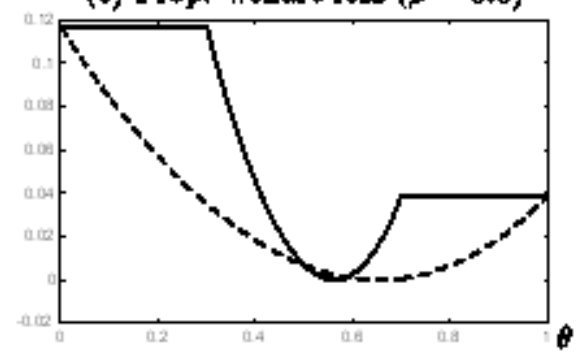

(b) Prop. walfare lose $(\beta=0.243)$

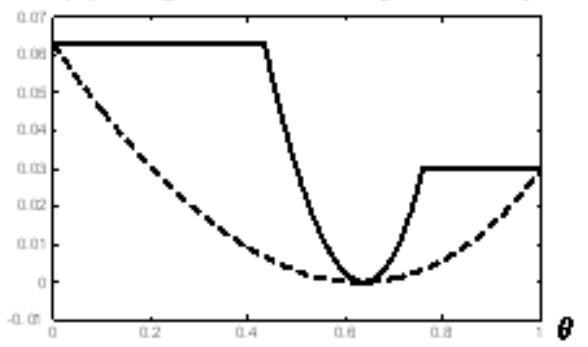

Figure 5: Welfare loss as a function of $\theta$. Solid curve: with strategic interaction; dashed curve: without strategic interaction.

\subsection{Heterogeneity}

Even if we remove time inconsistency and strategic interaction from the model, the decentralized tax rates are likely to deviate from the first-best tax rate. What is the reason

\footnotetext{
${ }^{20}$ The underlying set of parameters is described in Table 2 below.

${ }^{21}$ For this parameter constellation $\tau_{f b}$ equals the decentralized tax rate for $\theta^{*}=\frac{\alpha-q+\beta(1-\alpha)}{\alpha+\beta-q(1+\beta)}$, which, by construction, is the same under strategic interaction and absence of strategic interaction.
} 
for this remaining inefficiency ${ }^{22}$ This residual inefficiency must be due to a fundamental conflict of interest. Since both groups are asymmetrically affected by changes in the tax rate, every group prefers a different tax rate. However, heterogeneity is not sufficient for inefficiency to occur. From the median voter model we know that political competition, based on the median voter principle, delivers an efficient solution provided that the income distribution is symmetric. In this case, the first-best tax rate coincides with the preferred tax rate of the median voter (decisive voter).

Our model departs along two dimensions from this benchmark case. First, we do not apply the median voter principle and, second, the income distribution is discrete with two realizations ("income of workers" and "income of capitalists"). In this case, there is simply no voter who prefers the first-best tax rate. Consequently, there is no decentralized decision mechanism, relying on the principle of one voter being decisive, that can deliver the first-best solution.

The remaining inefficiency can be labelled "natural inefficiency" since it could only be avoided by an omnipotent social planner who sets the tax rate to its first-best level. Put differently, the decentralized economy is intrinsically characterized by a conflict of interest between the two classes. Since both groups are asymmetrically affected by changes in the tax rate, the political process is likely to give rise to a tax rate different from the first-best tax rate. Hence, the conflict of interest produces an additional inefficiency.

\section{Numerical considerations}

\subsection{The overall distributional-conflict inefficiency}

The quantitative importance of the overall distributional-conflict inefficiency is assessed by running a simple numerical exercise. To this end, we calibrate the general equilibrium model under study, determine the different tax rates, and calculate the implied welfare loss. In addition, the relative importance of the different mechanisms discussed above is investigated. Table 2 shows the underlying baseline set of parameters.

Table 2: Baseline set of parameters.

\begin{tabular}{|l|c|}
\hline Technology and endowment & $\alpha=0.3 ; \beta=0.25 L=5 ; u=0.6 ; K=20$ \\
\hline Policy and capital outside option & $q=0.6 ; \bar{r}=0.1 ; \varepsilon=0.1$ \\
\hline
\end{tabular}

The empirical literature on productive government expenditures indicates that the elasticity of productive government expenditures in the production of final output should lie in the interval $\beta \in[0.16,0.39]$ (Aschauer, 1989; Finn, 1993). ${ }^{23}$ The choice of $q=0.6$ is compatible with data on social security transfers in OECD countries. More precisely, expenditures on social security transfers as a percentage of total tax receipts, $1-q$ in our notation, averaged to $35 \%$ in 2000 (OECD, 2006). Since the definition of "social security transfers" is somewhat narrow in the context of the model, we set $1-q=0.4{ }^{24}$ The capital share of $\alpha=0.3$ is standard. The assumption $u=0.6$ means that individuals supply $60 \%$

\footnotetext{
${ }^{22}$ Notice that productive government expenditures $G$ do not cause an ineffiency in this model. It is true that $G$ represents an external effect from the perspective of the representative firm. However, when deciding on the preferred tax rate individuals internalize the associated change in $G$.

${ }^{23}$ For a detailed discussion on the empirical estimation see Glomm and Ravikumar (1997).

${ }^{24}$ Public social expenditure as a percentage of total tax receipts among OECD countries averaged to 0.6 in 2000 (OECD, 2006). This defintion would, however, be too broad.
} 
of their time endowment (net of recreation) to the labor market. The outside option for capital $\bar{r}=0.1$ might appear somewhat high at first glance. However, the implied rate of return on capital earned in the outside option net of investment costs (associated with foreign investments) amounts to 0.066 (more precisely, $\bar{r}-\varepsilon \frac{K-K_{M}(\tau=0.4)}{K} \cong 0.066$ ).

Employing the baseline set of parameters in Table 2 leads to the following tax rates:

$$
\tau_{D C}^{*} \cong 0.25 ; \quad \tau_{f b} \cong 0.37 ; \quad \tau_{L}^{o p t} \cong 0.43 ; \quad \tau_{D L}^{*} \cong 0.58
$$

Notice that these tax rates are fairly plausible in empirical terms. We now turn to the overall distributional-conflict inefficiency, as measured by $\frac{y\left(\tau_{f b}\right)-y\left(\tau^{*}\right)}{y\left(\tau_{f b}\right)}$. The decentralized tax rate $\tau^{*}$ depends on the presence or absence of strategic interaction and, additionally, on the value of the political impact parameter $\theta$. Assuming, first, strategic interaction among capitalists and workers in the political process, and, second, that the economy is in a dominance of workers regime $\left(\theta \leq \frac{q-\alpha-\beta(1-\alpha)}{q-\alpha}\right)$ we get:

$$
\frac{y\left(\tau_{f b}=0.37\right)-y\left(\tau_{D L}^{*}=0.58\right)}{y\left(\tau_{f b}=0.37\right)} \cong 0.073 .
$$

The proportional gap between aggregate income evaluated at the first-best tax rate $\tau_{f b} \cong 0.37$ and aggregate income evaluated at the decentralized tax rate $\tau_{D L}^{*} \cong 0.58$ hence amounts to $7.3 \%$. This number points to a substantial welfare loss and indicates that the inefficiency due to distributional conflicts may be substantial. ${ }^{25}$

\subsection{A decomposition into several components}

We finally turn to the relative importance of the different mechanisms discussed in Section 6. Figure 6, upper plot, shows the overall distributional-conflict inefficiency together with the three components "time inconsistency", "strategic interaction", and "heterogeneity" as a function of $\theta$. The curve labelled "overall gap" gives the absolute gap $\Delta y=y\left(\tau_{f b}\right)-$ $y\left(\tau^{*}(\theta)\right) .{ }^{26}$ As explained above (Figure 5) this curve has three ranges, which correspond to the three different regimes ("dominance of workers", "no group dominates", "dominance of capitalists"). The lower plot reproduces Figure 3 to ease the interpretation.

The curve labelled "strat. int." displays the inefficiency due to strategic interaction among major interest groups. To be precise, this curve shows the loss in output due to the fact that there is strategic interaction in the political process when the time inconsistency problem is still prevalent. For $\theta=0$ and $\theta=1$ this component must be zero since, in these cases, the decentralized tax rate with strategic interaction and without strategic interaction coincide. The difference $\Delta \tau=\left|\tau^{*}-\tau_{f b}\right|$ and hence the gap $\Delta y$ increases initially, starting at $\theta=0$, as $\theta$ rises. This is due to the fact that the decentralized tax rate remains constant under strategic interaction as long as the economy is in a dominance of workers regime, while the tax rate decreases with $\theta$ from the beginning under absence of strategic interaction. However, when $\theta$ passes a critical threshold, given by $\theta=\frac{1-q}{\alpha-q} \beta$, and hence the economy enters into a "no group dominates regime" the decentralized tax rate decreases stronger under strategic interaction compared to the case of no strategic interaction and hence the

\footnotetext{
${ }^{25}$ Two remarks are at order: First, the $7 \%$ is much larger than the output gap during severe recessions, which amounts to approximately $3 \%$. Second, in a dynamic growth model the upward bias in the tax rate would translate into a downward bias in the growth rate. Therefore, the welfare loss would be even larger in a dynamic setup.

${ }^{26}$ We use the absolute gap here since the corresponding plot for the proportional gap is more difficult to interpret.
} 
curve "strat. int." peaks at $\theta=\frac{1-q}{\alpha-q} \beta$. It then approaches zero at the unique $\theta$ which implies that the decentralized tax rate with strategic interaction and without strategic interaction coincide (for the set of parameters this is also the value of $\theta$ which establishes the first best such that the overall gap also vanishes at this point). Increasing $\theta$ further leads once more to an increase, a peak at $\theta=1-\beta$, and eventually a reversal to zero as $\theta$ goes to unity.

The curve labelled "time inconsist." shows the time-inconsistency component. This curve assumes that (i) there is no strategic interaction, i.e. all relevant tax rates lie on the straight line given by $\tilde{\tau}^{*}=\theta \beta+(1-\theta) \frac{(\alpha-1) \beta}{\alpha-q}$, and (ii) workers demand $\tau_{D L}^{*}$ (i.e. do not take the feedback effect of capital flights into account) instead of $\tau_{L}^{o p t}$, which is optimal in the sense of taking the feedback effect of capital flights into account. For $\theta=0$ this component is positive since workers alone determine the decentralized tax rate, which is too high compared to the first best. When $\theta$ is increased (i.e. workers become less and less influential), the time inconsistency component falls as the worker's political impact gets smaller. It can be recognized that the time-inconsistency component turns even negative. For a sufficiently high value of $\theta$ (i.e. a strong position of capitalists) the decentralized tax rate might be lower than the first best. Time inconsistency leads workers to opt for a higher tax rate which moves the decentralized tax rate closer to the first best. In this case, the isolated contribution of time inconsistency is positive (2nd best implication). The time inconsistency component reverts to zero as $\theta$ further increases. The reason is that the workers' political impact becomes smaller and eventually vanishes.

Finally, the curve labeled "heterogeneity" gives the residual inefficiency, which, as explained above, can be attributed to heterogeneity and the associated fundamental conflict of interests. Figure 6 shows that the heterogeneity component is positive initially. Let's once more start with $\theta=0$. In this case, the decentralized tax rate is $\tau_{L}^{o p t}$ since (i) there is no strategic interaction, hence the decentralized tax rate is formed according to (14), and (ii) $\tau_{D L}^{*}=\tau_{L}^{o p t}$. Since $\tau_{L}^{o p t} \neq \tau_{f b}$ a residual inefficiency remains even after strategic interaction and time inconsistency have been removed. Increasing $\theta$ moves $\tau^{*}$ closer to $\tau_{f b}$ and hence the heterogeneity component falls. There is a critical value of $\theta$, determined by $\theta \beta+(1-\theta) \tau_{L}^{o p t}=\tau_{f b}$, at which the heterogeneity component vanishes. When $\theta$ is further increased the gap $\Delta \tau=\left|\theta \beta+(1-\theta) \tau_{L}^{o p t}-\tau_{f b}\right|$ is widened and the heterogeneity component rises. At $\theta=1$ the overall distributional-conflict inefficiency is made up exclusively of the inefficiency due to heterogeneity since both the strategic-interaction and the time-inconsistency components vanish at $\theta=1$. 


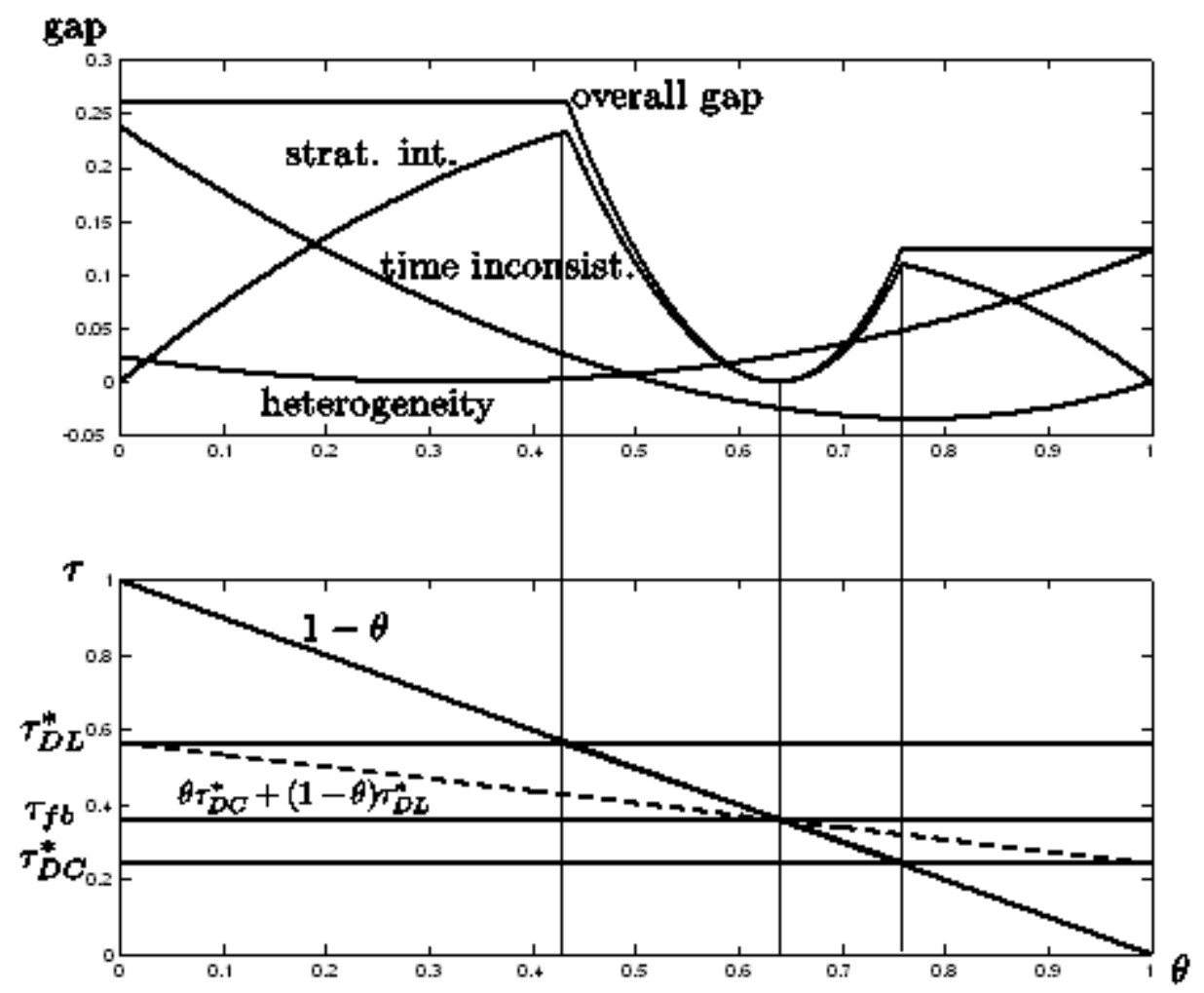

Figure 6: Decomposition of overall distributional-conflict inefficiency.

\section{Summary and conclusion}

The starting point for this paper is the recognition that distributional conflicts prevail in every market economy. We believe that the way these conflicts are carried out has first order implications for economic efficiency and welfare. Employing a simple general equilibrium model, which captures the major relevant features, we have investigated the sources and consequences of distributional-conflict inefficiencies. The main contribution of the paper lies in the decomposition of the distributional-conflict inefficiency into three components: (i) the time-inconsistency component; (ii) strategic interaction in the political sphere; and (ii) an unavoidable residual which results from heterogeneity. Furthermore, using data for OECD economies we have used a calibrated version of the model to assess the magnitude of the distributional-conflict inefficiency. This exercise indicates that the inefficiency may be quite substantial. For our baseline set of parameters we find an output loss of about $7 \%$ (recall that severe recessions are associated with an output gap of around 3\%). Numerical considerations have, in addition, been used to assess the relative importance of the different components.

These results leave us with a natural follow-up question: What are the mechanisms that have the potential to reduce the distributional-conflict inefficiency. Since a discussion of this topic would clearly constitute a separate paper, we restrict ourselves here to the following enumeration. There appear to be four such "mechanisms": (i) One obvious possibility lies in the reduction of income heterogeneity, which could be induced by appropriate government 
policies. (ii) At a theoretical level, one could think of a wage contract implying that workers exchange a share of their wage income against a claim on the capital income net of taxes. As a result, it becomes incentive-compatible for workers to opt for a comparably low tax rate at the ex post investment stage. (iii) A mechanism which is at work in reality lies in repeated interaction in the political process. We did not model this aspect to keep the analysis as simple as possible. It is important to notice, in this context, that the politicalinstitutional system then determines the relevant time horizon. (iv) It appears interesting to consider the consequences of inequality aversion as a fundamental cultural factor (Fehr and Schmidt, 1999). Tyran and Sausgruber (2006) have shown that "a small degree of inequality aversion" can lead to large equilibrium redistribution. In an open economy, then, it seems that inequality aversion indeed magnifies the output loss due to distributional conflicts.

Finally, the paper at hand contributes to the theoretical literature, which tries to understand the differences in per capita income across countries. Recent macroeconomic studies have decomposed the international variance of per capita income into three basic components (Caselli, 2005): (i) physical inputs; (ii) technology; (iii) institutions and policy. Olson (1996) has argued that the third component is substantial. We have shown that policy choices are shaped by distributional conflicts and the way these conflicts are carried out. Our quantitative finding suggests that the distributional-conflict inefficiency can indeed be substantial, which is in line with Olson's results.

\section{References}

[1] Acemoglu, Daron, Why Not a Political Coase Theorem? Social Conflict, Commitment, and Politics, December 2003, Journal of the Comparative Economic.

[2] Acemoglu, Daron, Georgy Egorov and Konstantin Sonin, Coalition Formation in Political Games, Working Paper w0090, Center for Economic and Financial Research (CEFIR), 2006.

[3] Alesina, A. and D. Rodrick, Distribution and Growth, Quarterly Journal of Economics, 1994, Vol. 109, 465-490.

[4] Aschauer, David A, Is Public Expenditure Productive? Journal of Monetary Economics, 1989, No 23, 177-200.

[5] Barro, R.J., Government Spending in a Simple Model of Endogenous Growth, Journal of Political Economy, 1990, Vol. 98, No. 2, S103-S125.

[6] Becker, Garry S., A Theory of Competition among Pressure Groups for Political Influence, Quarterly Journal of Economics, 1983, Vol. XCVIII, No. 3, 371-400.

[7] Benhabib, J. and A. Rustichini, Social Conflict and Growth, Journal of Economic Growth, 1996, Vol. 1, 125-142.

[8] Bertola, Giuseppe (1993); "Factor Shares and Savings in Endogenous Growth," American Economic Review, 83, 1184-1198.

[9] Caselli, Francesco, Accounting for Cross-Country Income Differences, Handbook of Economic Growth, P. Aghion and S. Durlauf (eds.), Elsevier 2005.

[10] Elster, J., The Case for Methodological Individualism, Theory and Society, 1982, 11 (4), 453-482. 
[11] Fehr, E. and Schmidt, K. M. (1999), "A Theory of Fairness, Competition and Cooperation." Quarterly Journal of Economics 114, 817-868.

[12] Finn, M. (1993). Is All Government Capital Produvtive ? Federal Reserve Bank of Richmond, Economic Quarterly 79, 58-80.

[13] Fischer, S. (1980), "Dynamic inconsistency, cooperation, and the benevolent dissemblinggovernment", Journal of Economic Dynamics and Control, 2, 93-107.

[14] Glomm, Gerhard \& Ravikumar, B., 1997. "Productive government expenditures and long-run growth," Journal of Economic Dynamics and Control, Vol. 21(1), 183-204.

[15] Golden, Miriam; Peter Lange; and Michael Wallerstein. 2006. "Union Centralization among Advanced Industrial Societies: An Empirical Study." Version dated June 16, 2006 .

[16] González, Francisco M. and Hugh M. Neary, Optimal Growth Policy Under Privately Enforced Property Rights, Working Paper UBC, 2005, Vancouver.

[17] Hassler, John, Jose V. Rodriguez Mora, Kjetil Storesletten, Fabrizio Zilibotti, The Survival of the Welfare State, American Economic Review, 2003, Vol. 93, No. 1, 87112.

[18] ILO, Statistics of trade union membership, ILO Bureau of Statistics, 2006.

[19] Kydland, Finn E \& Prescott, Edward C, 1977. "Rules Rather Than Discretion: The Inconsistency of Optimal Plans," Journal of Political Economy, University of Chicago Press, vol. 85(3), pages 473-91, June.

[20] Lancaster, K., The dynamic inefficiency of capitalism, Journal of Political Economy, 1973, 81 (5), 1092-1109.

[21] Lejour, A. M. and H. A. A. Verbon, Tax Competition and Redistribution in a TwoCountry Endogenous-Growth Model, International Tax and Public Finance, 4, 485-497 (1997).

[22] Medina, F., The Comparative Statics of Collective Action: A Pragmatic Approach to Games with Multiple Equilibria, Rationality and Society, 2006, forthcoming.

[23] Meltzer, Allan H. and Scott F. Richard. 1981. "A Rational Theory of the Size of Government," Journal of Political Economy 89:914-27.

[24] OECD Factbook 2006: Economic, Environmental and Social Statistics - ISBN 92-6403561-3 - (c) OECD 2006.

[25] Olson, Mancur (1996). Big bills left on the sidewalk: why some nations are rich, and others poor. Journal of Economic Perspectives, 10(2), Spring 1996, 3-24.

[26] Persson, T., and G. Tabellini. (1991). "The Politics of 1992: Fiscal Policy and European Integration." CEPR Discussion Paper 501.

[27] Persson T. and Tabellini G., (1994), "Is Inequality Harmful for Growth? Theory and Evidence", American Economic Review, Vol 84, 600-621. 
[28] Persson, Torsten und Guido Tabellini (2000): "Political economics: explaining economic policy", MIT Press Cambridge, Massachusetts, London.

[29] Roberts, Kevin W.S. 1977. "Voting over Income Tax Schedules," Journal of Public Economics. 8:329-340.

[30] Roemer, John E., Political Competition: Theory and Application, Harvard University Press, Cambridge, 2001.

[31] Romer, Thomas. 1975. "Individual Welfare, Majority Voting, and the Properties of a Linear Income Tax," Journal of Public Economics. 14:163-185.

[32] Strulik, Holger, Social Composition, Social Conflict, and Economic Development, Working Paper, University of Copenhagen, September 2005.

[33] Sydsaeter, K., A. Strom, and P. Berck, Economists' Mathematical Manual, Springer Publisher, Berlin, 2000.

[34] Tyran, J.R. and R. Sausgruber, A little fairness may induce a lot of redistribution in democracy, European Economic Review, 2006, Vol. 50, No. 2, 469-485.

\section{Appendix}

\subsection{Reduced-form technology}

Using $G=q \tau Y_{M}$ together with $Y_{M}=G^{\beta} K_{M}^{\alpha}(u L)^{1-\alpha}$ we first solve for $G$ :

$$
\begin{gathered}
G=q \tau G^{\beta} K_{M}^{\alpha}(u L)^{1-\alpha} \\
G=\left(q \tau K_{M}^{\alpha}(u L)^{1-\alpha}\right)^{\frac{1}{1-\beta}} .
\end{gathered}
$$

Plugging this expression for $G$ back into $Y_{M}=G^{\beta} K_{M}^{\alpha}(u L)^{1-\alpha}$ gives:

$$
\begin{gathered}
Y_{M}=\left(q \tau K_{M}^{\alpha}(u L)^{1-\alpha}\right)^{\frac{\beta}{1-\beta}} K_{M}^{\alpha} L^{1-\alpha} \\
Y_{M}=q^{\frac{\beta}{1-\beta}} \tau^{\frac{\beta}{1-\beta}} K_{M}^{\frac{\beta \alpha}{1-\beta}+\alpha}(u L)^{\frac{\beta(1-\alpha)}{1-\beta}}+(1-\alpha) \\
Y_{M}=q^{\frac{\beta}{1-\beta}} \tau^{\frac{\beta}{1-\beta}} K_{M}^{\frac{\alpha}{1-\beta}}(u L)^{\frac{1-\alpha}{1-\beta}} .
\end{gathered}
$$

This is equation (1) in the main text.

\subsection{Factor prices}

The competitive interest rate is given by: ${ }^{27}$

$$
\begin{gathered}
r=\frac{\partial Y_{M}}{\partial K_{M}}=\alpha G^{\beta} K_{M}^{\alpha-1}(u L)^{1-\alpha} \\
r=\alpha\left(q \tau K_{M}^{\alpha}(u L)^{1-\alpha}\right)^{\frac{\beta}{1-\beta}} K_{M}^{\alpha-1}(u L)^{1-\alpha}
\end{gathered}
$$

\footnotetext{
${ }^{27}$ Notice that it is necessary to first take the partial derivative w.r.t. $K$ or $L$ and then insert $G=$ $\left(q \tau K_{M}^{\alpha} L^{1-\alpha}\right)^{\frac{1}{1-\beta}}$.
} 


$$
r=\alpha(q \tau)^{\frac{\beta}{1-\beta}} K_{M}^{\frac{\alpha-1+\beta}{1-\beta}}(u L)^{\frac{1-\alpha}{1-\beta}}
$$

This is equation (3) in the main text.

The competitive wage rate reads:

$$
\begin{gathered}
w=\frac{\partial Y_{M}}{\partial L}=(1-\alpha) G^{\beta} K_{M}^{\alpha}(u L)^{-\alpha} \\
w=(1-\alpha)\left(q \tau K_{M}^{\alpha}(u L)^{1-\alpha}\right)^{\frac{\beta}{1-\beta}} K_{M}^{\alpha}(u L)^{-\alpha} \\
w=(1-\alpha)(q \tau)^{\frac{\beta}{1-\beta}} K_{M}^{\frac{\alpha}{1-\beta}}(u L)^{\frac{\beta-\alpha}{1-\beta}}
\end{gathered}
$$

This is equation (4) in the main text.

\subsection{Reaction function of capitalists}

The maximization problem of capitalists can be expressed as follows:

$$
\begin{aligned}
& \max _{\tau_{C}}\left\{y^{K}(\tau)=(1-\tau) \alpha(q \tau)^{\frac{\beta}{1-\beta}} K_{M}^{\frac{\alpha-1+\beta}{1-\beta}}(u L)^{\frac{1-\alpha}{1-\beta}} K_{M}\right\} \\
& \text { s.t. } \tau=\theta \tau_{C}+(1-\theta) \tau_{L} \\
& \text { and } 0 \leq \tau_{C} \leq 1
\end{aligned}
$$

given the worker's vote and $0 \leq \tau_{L} \leq 1$ satisfying $0 \leq \tau \leq 1$. Formulating the Lagrangian yields

$$
L=y^{K}(\tau)+\lambda_{0}\left(-\tau_{C}\right)+\lambda_{1}\left(1-\tau_{C}\right) .
$$

The Kuhn-Tucker conditions can be stated as follows (Sydsaeter et al., 2000, pp. 97)

$$
\begin{aligned}
\text { (A) } \tau_{C} \frac{\partial L}{\partial \tau_{C}} & =\tau_{C}\left(\frac{\partial y^{K}}{\partial \tau_{C}}-\lambda_{0}-\lambda_{1}\right)=0 . \\
\text { (B) } \lambda_{0} \frac{\partial L}{\partial \lambda_{0}} & =\lambda_{0} \tau_{C}=0 \\
\text { (C) } \lambda_{1} \frac{\partial L}{\partial \lambda_{1}} & =\lambda_{1}\left(1-\tau_{C}\right)=0 .
\end{aligned}
$$

1. $\lambda_{1}=\lambda_{0}=0$ - no restriction is binding and there is an interior solution with $\frac{\partial y^{K}}{\partial \tau_{C}}=0$ : 


$$
\begin{aligned}
& -\theta \alpha(q \tau)^{\frac{\beta}{1-\beta}} K_{M}^{\frac{\alpha-1+\beta}{1-\beta}}(u L)^{\frac{1-\alpha}{1-\beta}} K_{M} \\
& +(1-\tau) \theta \alpha \frac{\beta}{1-\beta}(q)^{\frac{\beta}{1-\beta}} \tau^{\frac{2 \beta-1}{1-\beta}} K_{M}^{\frac{\alpha-1+\beta}{1-\beta}}(u L)^{\frac{1-\alpha}{1-\beta}} K_{M}=0 \\
& -\tau^{\frac{\beta}{1-\beta}}+(1-\tau) \frac{\beta}{1-\beta} \tau^{\frac{2 \beta-1}{1-\beta}}=0 \\
& -\tau^{\frac{\beta}{1-\beta}}-\frac{\beta}{1-\beta} \tau^{\frac{\beta}{1-\beta}}+\frac{\beta}{1-\beta} \tau^{\frac{2 \beta-1}{1-\beta}}=0 \\
& -1+\frac{\beta}{1-\beta} \tau^{-1}-\frac{\beta}{1-\beta}=0 \\
& -\frac{\beta}{1-\beta}+\frac{\beta}{1-\beta} \tau^{-1}=0 \\
& \tau^{-1}=\frac{1}{\beta}
\end{aligned}
$$

such that

$$
\theta \tau_{C}+(1-\tau) \tau_{L}=\beta
$$

and hence

$$
\tau_{C}=\frac{\beta}{\theta}-\frac{1-\theta}{\theta} \tau_{L}
$$

2. $\lambda_{1}=0$ and $\lambda_{0} \neq 0$ - negative tax rates are excluded, such that in light of condition $(B): \tau_{C}=0$. If this is the case, we yield from $(A): \frac{\partial y^{K}}{\partial \tau_{C}}=\lambda_{0}$. Since, we have for interior solutions $\frac{\partial y^{K}}{\partial \tau_{C}}=0$, we yield $\frac{\partial y^{K}}{\partial \tau_{C}}<0$ and therefore $\frac{\beta}{\theta}-\frac{1-\theta}{\theta} \tau_{L}<0$.

3. $\lambda_{1} \neq 0$ and $\lambda_{0}=0$ - tax rates greater then one are excluded. Hence, we get from $(C): \tau_{C}=1$ and from $(A): \frac{\partial y^{K}}{\partial \tau_{C}}=\lambda_{0}$, where $\frac{\partial y^{K}}{\partial \tau_{C}}>0$ implying that $\frac{\beta}{\theta}-\frac{1-\theta}{\theta} \tau_{L}>1$.

Collecting all the feasible outcomes for $\tau_{C}$ together, yields

$$
\tau_{C}=\left\{\begin{array}{cccc}
1 & \text { for } & \frac{\beta}{\theta}-\frac{1-\theta}{\theta} \tau_{L} & >1 \\
\frac{\beta}{\theta}-\frac{1-\theta}{\theta} \tau_{L} & \text { for } & 0 \leq \frac{\beta}{\theta}-\frac{1-\theta}{\theta} \tau_{L} & \leq 1 \\
0 & \text { for } & \frac{\beta}{\theta}-\frac{1-\theta}{\theta} \tau_{L} & <0
\end{array}\right.
$$

\subsection{Reaction function of workers}

The workers' maximization problem of is:

$$
\begin{aligned}
& \max _{\tau_{L}}\left\{y^{L}(\tau)=(1-\tau)(1-\alpha)(q \tau)^{\frac{\beta}{1-\beta}} K_{M}^{\frac{\alpha}{1-\beta}}(u L)^{\frac{\beta-\alpha}{1-\beta}} L+(1-q) \tau q^{\frac{\beta}{1-\beta}} \tau^{\frac{\beta}{1-\beta}} K_{M}^{\frac{\alpha}{1-\beta}}(u L)^{\frac{1-\alpha}{1-\beta}}\right\} \\
& \text { s.t. } \quad \tau=\theta \tau_{C}+(1-\theta) \tau_{L} \\
& \text { and } 0 \leq \tau_{L} \leq 1,
\end{aligned}
$$

given the capitalists' vote and $0 \leq \tau_{C} \leq 1$ satisfying $0 \leq \tau \leq 1$. Formulating the Lagrangian yields

$$
L=y^{L}(\tau)+\lambda_{0}\left(-\tau_{L}\right)+\lambda_{1}\left(1-\tau_{L}\right)
$$


The Kuhn-Tucker conditions can be stated as follows (Sydsaeter et al., 2000, pp. 97)

$$
\begin{aligned}
\left(A^{\prime}\right) \tau_{L} \frac{\partial L}{\partial \tau_{L}} & =\tau_{L}\left(\frac{\partial y^{L}}{\partial \tau_{L}}-\lambda_{0}-\lambda_{1}\right)=0 . \\
\left(B^{\prime}\right) \lambda_{0} \frac{\partial L}{\partial \lambda_{0}} & =\lambda_{0} \tau_{L}=0 \\
\left(C^{\prime}\right) \lambda_{1} \frac{\partial L}{\partial \lambda_{1}} & =\lambda_{1}\left(1-\tau_{L}\right)=0 .
\end{aligned}
$$

1. $\lambda_{1}=\lambda_{0}=0$ - no restriction is binding and there is an interior solution with $\frac{\partial y^{L}}{\partial \tau_{L}}=0$ :

$$
\begin{aligned}
& (1-\theta)(1-\alpha)(q \tau)^{\frac{\beta}{1-\beta}} K_{M}^{\frac{\alpha}{1-\beta}}(u L)^{\frac{\beta-\alpha}{1-\beta}} L \\
& +(1-\tau) \frac{\beta}{1-\beta}(1-\alpha)(1-\theta)(q)^{\frac{\beta}{1-\beta}} \tau^{\frac{2 \beta-\beta}{1-\beta}} K_{M}^{\frac{\alpha}{1-\beta}}(u L)^{\frac{\beta-\alpha}{1-\beta}} u L \\
& +(1-q) \frac{1}{1-\beta}(1-\theta)(q)^{\frac{\beta}{1-\beta}} \tau^{\frac{\beta}{1-\beta}} K_{M}^{\frac{\alpha}{1-\beta}}(u L)^{\frac{1-\alpha}{1-\beta}}(u L)=0 \\
& -(1-\alpha) \tau^{\frac{\beta}{1-\beta}}+(1-\tau)(1-\alpha) \frac{\beta}{1-\beta} \tau^{\frac{2 \beta-1}{1-\beta}}+(1-q) \frac{\beta}{1-\beta} \tau^{\frac{\beta}{1-\beta}}=0 \\
& -(1-\alpha) \tau^{\frac{\beta}{1-\beta}}+(1-\alpha) \frac{\beta}{1-\beta} \tau^{\frac{2 \beta-1}{1-\beta}}-(1-\alpha) \frac{\beta}{1-\beta} \tau^{\frac{\beta}{1-\beta}}+(1-q) \frac{\beta}{1-\beta} \tau^{\frac{\beta}{1-\beta}}=0 \\
& -(1-\alpha) \tau^{\frac{\beta}{1-\beta}}\left(\frac{1}{1-\beta}\right)+(1-\alpha) \frac{\beta}{1-\beta} \tau^{\frac{2 \beta-1}{1-\beta}}+(1-q) \frac{\beta}{1-\beta} \tau^{\frac{\beta}{1-\beta}}=0 \\
& \tau^{\frac{\beta}{1-\beta}}(\alpha-q)+(1-\alpha) \beta \tau^{\frac{2 \beta-1}{1-\beta}}=0
\end{aligned}
$$

implying that

$$
\begin{aligned}
& \alpha-q+(1-\alpha) \beta \tau^{-1}=0 \\
\Rightarrow \quad & \alpha-q=(\alpha-1) \beta \tau^{-1}
\end{aligned}
$$

and hence

$$
\begin{aligned}
& \frac{\alpha-1}{\alpha-q} \beta=\theta \tau_{C}+(1-\theta) \tau_{L} \\
& \tau_{L}=\frac{(\alpha-1) \beta}{(1-\theta)(\alpha-q)}-\frac{\theta}{1-\theta} \tau_{C}
\end{aligned}
$$

2. $\lambda_{1}=0$ and $\lambda_{0} \neq 0$ - negative tax rates are excluded, such that in light of condition $\left(B^{\prime}\right): \tau_{L}=0$. If this is the case, we yield from $\left(A^{\prime}\right): \frac{\partial y^{L}}{\partial \tau_{L}}=\lambda_{0}$. Since, we have for interior solutions $\frac{\partial y^{L}}{\partial \tau_{L}}=0$, we yield $\frac{\partial y^{K}}{\partial \tau_{L}}<0$ and therefore $\frac{(\alpha-1) \beta}{(1-\theta)(\alpha-q)}-\frac{\theta}{1-\theta} \tau_{C}<0$.

3. $\lambda_{1} \neq 0$ and $\lambda_{0}=0$ - tax rates greater then one are excluded. Hence, we get from $\left(C^{\prime}\right): \tau_{L}=1$ and from $\left(A^{\prime}\right): \frac{\partial y^{L}}{\partial \tau_{L}}=\lambda_{0}$, where $\frac{\partial y^{L}}{\partial \tau_{L}}>0$ implying that $\frac{(\alpha-1) \beta}{(1-\theta)(\alpha-q)}-$ $\frac{\theta}{1-\theta} \tau_{C}>1$. 
Collecting all the feasible outcomes for $\tau_{L}$ together, yields

$$
\tau_{L}=\left\{\begin{array}{cccc}
1 & \text { for } & \frac{(\alpha-1) \beta}{(1-\theta)(\alpha-q)}-\frac{\theta}{1-\theta} \tau_{C} & >1 \\
\frac{(\alpha-1) \beta}{(1-\theta)(\alpha-q)}-\frac{\theta}{1-\theta} \tau_{C} & \text { for } & 0 \leq \frac{(\alpha-1) \beta}{(1-\theta)(\alpha-q)}-\frac{\theta}{1-\theta} \tau_{C} & \leq 1 \\
0 & \text { for } & \frac{(\alpha-1) \beta}{(1-\theta)(\alpha-q)}-\frac{\theta}{1-\theta} \tau_{C} & <0
\end{array}\right.
$$

\subsection{First-best tax rate - no outside option}

\section{Maximization of aggregate income}

Forming the first-order condition w.r.t $\tau$ in problem (19) yields after some manipulations

$$
-\alpha \tau^{\frac{\beta}{1-\beta}}+\frac{(1-\tau) \alpha \beta}{1-\beta} \tau^{\frac{2 \beta-1}{1-\beta}}+(1-q) \tau^{\frac{\beta}{1-\beta}}+(1-q) \tau^{\frac{\beta}{1-\beta}}=0 .
$$

Hence,

$$
-\alpha(1-\beta)-(1-\alpha)(1-\beta)+\beta\left(\frac{1}{\tau}-1\right)+(1-q)=0
$$

which implies immediately that

$$
\tau_{f b}=\frac{\beta}{q}
$$

This is equation (20) in the main text. 


\section{CESifo Working Paper Series}

(for full list see www.cesifo-group.de)

1944 Panu Poutvaara and Mikael Priks, Unemployment and Gang Crime: Could Prosperity Backfire?, March 2007

1945 Burkhard Heer, On the Modeling of the Income Distribution Business Cycle Dynamics, March 2007

1946 Christoph A. Schaltegger and Lars P. Feld, Are Fiscal Adjustments less Successful in Decentralized Governments?, March 2007

1947 Giovanni Facchini, Marcelo Olarreaga, Peri Silva and Gerald Willmann, Substitutability and Protectionism: Latin America's Trade Policy and Imports from China and India, March 2007

1948 C. Mirjam van Praag and Bernard M. S. van Praag, The Benefits of Being Economics Professor A (and not Z), March 2007

1949 Astrid Hopfensitz and Frans van Winden, Dynamic Choice, Independence and Emotions, March 2007

1950 Guglielmo Maria Caporale and Luis A. Gil-Alana, A Multivariate Long-Memory Model with Structural Breaks, March 2007

1951 Mattias Ganslandt and Keith E. Maskus, Wholesale Price Discrimination and Parallel Imports, March 2007

1952 Michela Redoano, Fiscal Interactions Among European Countries. Does the EU Matter?, March 2007

1953 Stefan C. Wolter, Rémy Hübschi and Matthias Müller, Push or Pull? An Empirical Analysis of the Demand for Individual Project Grants from the Swiss National Science Foundation, March 2007

1954 Scott Alan Carson, African-American and White Inequality in the American South: Evidence from the $19^{\text {th }}$ Century Missouri State Prison, March 2007

1955 Peter Egger, Marko Koethenbuerger and Michael Smart, Do Fiscal Transfers Alleviate Business Tax Competition? Evidence from Germany, March 2007

1956 Panu Poutvaara and Lars-H. R. Siemers, Smoking and Social Interaction, March 2007

1957 Stephan Danninger and Fred Joutz, What Explains Germany's Rebounding Export Market Share?, March 2007

1958 Stefan Krasa and Mattias Polborn, Majority-efficiency and Competition-efficiency in a Binary Policy Model, March 2007 
1959 Thiess Buettner and Georg Wamser, Intercompany Loans and Profit Shifting Evidence from Company-Level Data, March 2007

1960 Per Pettersson-Lidbom and Mikael Priks, Behavior under Social Pressure: Empty Italian Stadiums and Referee Bias, April 2007

1961 Balázs Égert and Carol S. Leonard, Dutch Disease Scare in Kazakhstan: Is it real?, April 2007

1962 Paul De Grauwe and Pablo Rovira Kaltwasser, Modeling Optimism and Pessimism in the Foreign Exchange Market, April 2007

1963 Volker Grossmann and Thomas M. Steger, Anti-Competitive Conduct, In-House R\&D, and Growth, April 2007

1964 Steven Brakman and Charles van Marrewijk, It's a Big World After All, April 2007

1965 Mauro Ghinamo, Paolo M. Panteghini and Federico Revelli, FDI Determination and Corporate Tax Competition in a Volatile World, April 2007

1966 Inés Macho-Stadler and David Pérez-Castrillo, Optimal Monitoring to Implement Clean Technologies when Pollution is Random, April 2007

1967 Thomas Eichner and Ruediger Pethig, Efficient $\mathrm{CO}_{2}$ Emissions Control with National Emissions Taxes and International Emissions Trading, April 2007

1968 Michela Redoano, Does Centralization Affect the Number and Size of Lobbies?, April 2007

1969 Christian Gollier, Intergenerational Risk-Sharing and Risk-Taking of a Pension Fund, April 2007

1970 Swapan K. Bhattacharya and Biswa N. Bhattacharyay, Gains and Losses of India-China Trade Cooperation - a Gravity Model Impact Analysis, April 2007

1971 Gerhard Illing, Financial Stability and Monetary Policy - A Framework, April 2007

1972 Rainald Borck and Matthias Wrede, Commuting Subsidies with two Transport Modes, April 2007

1973 Frederick van der Ploeg, Prudent Budgetary Policy: Political Economy of Precautionary Taxation, April 2007

1974 Ben J. Heijdra and Ward E. Romp, Retirement, Pensions, and Ageing, April 2007

1975 Scott Alan Carson, Health during Industrialization: Evidence from the $19^{\text {th }}$ Century Pennsylvania State Prison System, April 2007

1976 Andreas Haufler and Ian Wooton, Competition for Firms in an Oligopolistic Industry: Do Firms or Countries Have to Pay?, April 2007 
1977 Eckhard Janeba, Exports, Unemployment and the Welfare State, April 2007

1978 Gernot Doppelhofer and Melvyn Weeks, Jointness of Growth Determinants, April 2007

1979 Edith Sand and Assaf Razin, The Role of Immigration in Sustaining the Social Security System: A Political Economy Approach, April 2007

1980 Marco Pagano and Giovanni Immordino, Optimal Regulation of Auditing, May 2007

1981 Ludger Woessmann, Fundamental Determinants of School Efficiency and Equity: German States as a Microcosm for OECD Countries, May 2007

1982 Bas Jacobs, Real Options and Human Capital Investment, May 2007

1983 Steinar Holden and Fredrik Wulfsberg, Are Real Wages Rigid Downwards?, May 2007

1984 Cheng Hsiao, M. Hashem Pesaran and Andreas Pick, Diagnostic Tests of Cross Section Independence for Nonlinear Panel Data Models, May 2007

1985 Luis Otávio Façanha and Marcelo Resende, Hierarchical Structure in Brazilian Industrial Firms: An Econometric Study, May 2007

1986 Ondřej Schneider, The EU Budget Dispute - A Blessing in Disguise?, May2007

1987 Sascha O. Becker and Ludger Woessmann, Was Weber Wrong? A Human Capital Theory of Protestant Economic History, May 2007

1988 Erkki Koskela and Rune Stenbacka, Equilibrium Unemployment with Outsourcing and Wage Solidarity under Labour Market Imperfections, May 2007

1989 Guglielmo Maria Caporale, Juncal Cunado and Luis A. Gil-Alana, Deterministic versus Stochastic Seasonal Fractional Integration and Structural Breaks, May 2007

1990 Cláudia Costa Storti and Paul De Grauwe, Globalization and the Price Decline of Illicit Drugs, May 2007

1991 Thomas Eichner and Ruediger Pethig, Pricing the Ecosystem and Taxing Ecosystem Services: A General Equilibrium Approach, May 2007

1992 Wladimir Raymond, Pierre Mohnen, Franz Palm and Sybrand Schim van der Loeff, The Behavior of the Maximum Likelihood Estimator of Dynamic Panel Data Sample Selection Models, May 2007

1993 Fahad Khalil, Jacques Lawarrée and Sungho Yun, Bribery vs. Extortion: Allowing the Lesser of two Evils, May 2007

1994 Thorvaldur Gylfason, The International Economics of Natural Resources and Growth, May 2007 
1995 Catherine Roux and Thomas von Ungern-Sternberg, Leniency Programs in a Multimarket Setting: Amnesty Plus and Penalty Plus, May 2007

1996 J. Atsu Amegashie, Bazoumana Ouattara and Eric Strobl, Moral Hazard and the Composition of Transfers: Theory with an Application to Foreign Aid, May 2007

1997 Wolfgang Buchholz and Wolfgang Peters, Equal Sacrifice and Fair Burden Sharing in a Public Goods Economy, May 2007

1998 Robert S. Chirinko and Debdulal Mallick, The Fisher/Cobb-Douglas Paradox, Factor Shares, and Cointegration, May 2007

1999 Petra M. Geraats, Political Pressures and Monetary Mystique, May 2007

2000 Hartmut Egger and Udo Kreickemeier, Firm Heterogeneity and the Labour Market Effects of Trade Liberalisation, May 2007

2001 Andreas Freytag and Friedrich Schneider, Monetary Commitment, Institutional Constraints and Inflation: Empirical Evidence for OECD Countries since the 1970s, May 2007

2002 Niclas Berggren, Henrik Jordahl and Panu Poutvaara, The Looks of a Winner: Beauty, Gender, and Electoral Success, May 2007

2003 Tomer Blumkin, Yoram Margalioth and Efraim Sadka, Incorporating Affirmative Action into the Welfare State, May 2007

2004 Harrie A. A. Verbon, Migrating Football Players, Transfer Fees and Migration Controls, May 2007

2005 Helmuth Cremer, Jean-Marie Lozachmeur and Pierre Pestieau, Income Taxation of Couples and the Tax Unit Choice, May 2007

2006 Michele Moretto and Paolo M. Panteghini, Preemption, Start-Up Decisions and the Firms' Capital Structure, May 2007

2007 Andreas Schäfer and Thomas M. Steger, Macroeconomic Consequences of Distributional Conflicts, May 2007 